\title{
Leafhopper-Induced Activation of the Jasmonic Acid Response Benefits Salmonella enterica in a Flagellum-Dependent Manner
}

\author{
Kimberly N. Cowles ${ }^{1}$, Russell L. Groves ${ }^{2}$ and Jeri D. Barak ${ }^{1 *}$ \\ 1 Department of Plant Pathology, University of Wisconsin-Madison, Madison, WI, United States, ${ }^{2}$ Department \\ of Entomology, University of Wisconsin-Madison, Madison, WI, United States
}

OPEN ACCESS

Edited by:

Nicola Holden,

James Hutton Institute,

United Kingdom

Reviewed by:

Bradley L. Bearson,

United States Department

of Agriculture, United States

Masahiro Eguchi,

National Institute of Animal Health

(NARO), Japan

*Correspondence:

Jeri D. Barak

barak@plantpath.wisc.edu

Specialty section:

This article was submitted to

Plant Microbe Interactions,

a section of the journa

Frontiers in Microbiology

Received: 20 April 2018

Accepted: 07 August 2018

Published: 23 August 2018

Citation:

Cowles KN, Groves RL and Barak JD (2018) Leafhopper-Induced Activation of the Jasmonic Acid Response Benefits Salmonella enterica in a Flagellum-Dependent Manner.

Front. Microbiol. 9:1987.

doi: 10.3389/fmicb.2018.01987
Enteric human pathogens such as Salmonella enterica are typically studied in the context of their animal hosts, but it has become apparent that these bacteria spend a significant portion of their life cycle on plants. S. enterica survives the numerous stresses common to a plant niche, including defense responses, water and nutrient limitation, and exposure to UV irradiation leading to an increased potential for human disease. In fact, $S$. enterica is estimated to cause over one million cases of foodborne illness each year in the United States with $20 \%$ of those cases resulting from consumption of contaminated produce. Although $S$. enterica successfully persists in the plant environment, phytobacterial infection by Pectobacterium carotovorum or Xanthomonas spp. increases $S$. enterica survival and infrequently leads to growth on infected plants. The co-association of phytophagous insects, such as the Aster leafhopper, Macrosteles quadrilineatus, results in S. enterica populations that persist at higher levels for longer periods of time when compared to plants treated with $S$. enterica alone. We hypothesized that leafhoppers increase $S$. enterica persistence by altering the plant defense response to the benefit of the bacteria. Leafhopper infestation activated the jasmonic acid (JA) defense response while $S$. enterica colonization triggered the salicylic acid (SA) response. In tomato plants co-treated with S. enterica and leafhoppers, both JA- and SA-inducible genes were activated, suggesting that the presence of leafhoppers may affect the crosstalk that occurs between the two immune response pathways. To rule out the possibility that leafhoppers provide additional benefits to $S$. enterica, plants were treated with a chemical JA analog to activate the immune response in the absence of leafhoppers. Although bacterial populations continue to decline over time, analog treatment significantly increased bacterial persistence on the leaf surface. Bacterial mutant analysis determined that the bacterial flagellum, whether functional or not, was required for increased $S$. enterica survival after analog treatment. By investigating the interaction between this human pathogen, a common phytophagous insect, and their plant host, we hope to elucidate the mechanisms promoting $S$. enterica survival on plants and provide information to be used in the development of new food safety intervention strategies.

Keywords: biomultiplier, jasmonic acid, bacterial flagellum, plant immunity, pathogen-triggered immunity 


\section{INTRODUCTION}

According to the Centers for Disease Control and Prevention (CDC), the human enteric bacterial pathogen Salmonella enterica is estimated to cause disease in more than 1.2 million people annually in the United States. Salmonellosis is most often characterized by gastroenteritis that may result in diarrhea, fever, and abdominal cramping. Of the $S$. enterica-related illnesses that are acquired in the United States, more than $90 \%$ are estimated to have come from a food source with $46 \%$ involving fresh produce. S. enterica is ubiquitous in the plant environment, is commonly isolated from water sources used for irrigation or pesticide application, and persists for months on the roots and leaves of agricultural crops (Islam et al., 2004a,b; Haley et al., 2009). The phyllosphere (the above-ground parts of the plant) is a hostile environment with fluctuations in temperature, water and nutrient availability, and UV irradiation (O'Brien and Lindow, 1989; Islam et al., 2004b; Barak and Liang, 2008; PozaCarrion et al., 2013). The ability of S. enterica to overcome these environmental stresses contributes to the incidence of human disease due to the consumption of contaminated fresh produce (Gorski et al., 2011; Painter et al., 2013).

To survive on the leaf surface, epiphytic bacteria actively migrate to preferential niches such as trichomes, stomates, and cell junctions (Haefele and Lindow, 1987; Kinkel, 1997; Monier and Lindow, 2003; Remus-Emsermann et al., 2012). In these sites, bacteria find increased nutrient availability and protection against fluctuations in temperature, humidity, and UV radiation (Leveau and Lindow, 2001). In general, bacteria utilize many different types of motility, including swimming, swarming, twitching, gliding, and sliding (Henrichsen, 1972; Macnab, 1996; Mattick, 2002; Harshey, 2003; Mignot et al., 2007; Kearns, 2010). Perhaps the most well studied, swimming motility utilizes the flagellum to propel a bacterium through a semi-solid or liquid medium. The flagellum is a complex organelle in terms of both structure and regulation and is important for bacterial survival in many niches, including the surfaces of leaves (for recent review, see Rossez et al., 2015). For example, the plant pathogen Pseudomonas syringae requires flagellum-dependent swimming motility for full fitness on the surface of bean leaves. Motility mutants are less resistant to UV irradiation and desiccation, and mutant populations are reduced compared to the wildtype parent in colonization assays (Haefele and Lindow, 1987; Lindow et al., 1993). Similarly, S. enterica utilizes flagella for swimming and swarming motility, and flagella contribute to bacterial attachment to basil leaves (Berger et al., 2009).

Although the bacteria successfully locate preferred sites on the leaf surface, $S$. enterica populations slowly decline over time (Islam et al., 2004a,b; Barak et al., 2011). Unlike phytobacterial pathogens, $S$. enterica cannot liberate nutrients from the plant, leaving the human pathogen in an environment where resources are limiting. However, biotic factors, such as infection with phytobacterial pathogens, can release nutrients and allow for proliferation or enhanced survival of human bacterial pathogens. Depending on the species, Xanthomonas-induced necrosis and water-soaking leads to increased persistence of S. enterica serovar Typhimurium ( $S$. Typhimurium), or even replication in the case of Xanthomonas euvesicatoria and Xanthomonas gardneri, on tomato leaves (Potnis et al., 2014, 2015). Similarly, tissue damage caused by the soft-rotting bacterium Pectobacterium carotovorum subsp. carotovorum enhances $S$. Typhimurium persistence on romaine lettuce leaves (Kwan et al., 2013). Recently, our lab expanded the list of biological factors that enhance S. enterica survival (biomultipliers) to include phytophagous insects and demonstrated that insect infestation increases S. enterica persistence on plants (Soto-Arias et al., 2013, 2014). Specifically, the presence of Aster leafhopper (Macrosteles quadrilineatus), a common phloem-feeding pest of agricultural crops, significantly improved $S$. enterica persistence on lettuce leaves (Soto-Arias et al., 2013). Furthermore, phytophagous insects that encounter $S$. enterica-contaminated plants represent a risk for transmitting disease as they frequently move within and between plants while feeding and can be contaminated both externally and internally with S. enterica (Soto-Arias et al., 2014). Thus, phytophagous insects represent a risk factor for the dispersal of S. enterica amongst plants in an agricultural setting.

The mechanism(s) by which leafhopper infestation promotes $S$. enterica persistence on plants are unknown. Reviewing the list of environmental stresses present in this environment, we hypothesize that leafhoppers alter the plant immune response in a way that benefits bacterial survival on leaves. Plant immunity is characterized by a multi-layer defense response that is reminiscent of animal innate immunity. Pattern recognition receptors (PRRs) detect conserved pathogen associated molecular patterns (PAMPs) from invading microorganisms which trigger a cascade of responses (for reviews, see Garcia and Hirt, 2014; Melotto et al., 2014). Initially, the plant responds within seconds to minutes with changes in ion fluxes and extracellular alkalinization and increased production of reactive oxygen species (ROS). These changes are followed in the next minutes to hours with increases in ethylene production, stomatal closure, mitogen-activated protein kinase (MAPK) signaling, and transcriptional reprogramming. Within hours to days, accumulations in callose [ $\beta$ - $(1,3)$-glucan polymer] deposition, salicylic acid (SA) production, and defense gene transcription are observed. The defense hormones SA and jasmonic acid (JA) are well characterized signaling hormones critical to effective plant immunity. Generally, the SA pathway is induced by the plant in response to biotrophic pathogens while the JA pathway is activated in the presence of necrotrophic pathogens or chewing herbivores. Although not a strict rule, the SA and JA pathways are typically antagonistic; activation of one pathway leads to inhibition of the other (Pena-Cortes et al., 1993; van Wees et al., 2000; Spoel, 2003; Van der Does et al., 2013; Wei et al., 2014). Crosstalk between the two pathways is thought to fine tune the plant immune response to pathogens (Beckers and Spoel, 2006; Koornneef and Pieterse, 2008; Pieterse et al., 2012). Disruption or alteration of the SA and JA pathways could have downstream effects on the plant immune response and impact microbial survival.

Aster leafhoppers feed by inserting their stylets through plant cells to reach the phloem. Although this feeding style causes little cellular damage compared to chewing herbivores such as 
caterpillars, leafhoppers induce the JA response in Arabidopsis thaliana and tobacco (Nicotiana attenuata) plants (Sugio et al., 2011; Kallenbach et al., 2012). In contrast, in A. thaliana, Medicago truncatula, and lettuce (Lactuca sativa), inoculation with $S$. enterica leads to induction of the SA pathway (Iniguez et al., 2005; Klerks et al., 2007; Schikora et al., 2008; Jayaraman et al., 2014). Phytophagous insects have developed strategies to manipulate plant immunity to the benefit of the insect. As one example, the Colorado potato beetle (Leptinotarsa decemlineata) utilizes bacteria found in the beetle's oral secretions to reduce the JA response to the beetle by preemptively activating the SA response using the oral bacteria (Chung et al., 2013a,b). In this way, the beetle manipulates the host into responding to the bacteria, taking advantage of the antagonistic nature of the JA and SA pathways, and giving the herbivore, and their offspring, easier access to plant nutrients. The interaction between $S$. enterica and leafhoppers may not be as directly symbiotic as the Colorado potato beetle and its oral microflora, but we hypothesize that leafhopper-induced activation of the JA response may lead to antagonistic suppression of the SA response and indirectly create a more permissive environment for S. enterica.

In this study, we tested the hypothesis that infestation with leafhoppers alters the plant immune response and increases $S$. enterica persistence. Several multistate and international outbreaks have been linked to Salmonella-contaminated tomatoes (Cummings et al., 2001; Centers for Disease Control and Prevention, 2005, 2007; Gupta et al., 2007; Greene et al., 2008), making tomato a relevant plant host for studying $S$. enterica persistence. We chose to examine tomato plants as a way to compare the effects of leafhoppers on S. enterica populations in a second plant host. Additionally, we used the JA-inducible proteinase inhibitor gene pin 1 and the SA-inducible pathogenesis related protein gene prla1 as established markers (Tornero et al., 1994; Fowler et al., 2009) to monitor the two plant defense responses with quantitative PCR. Further, we examined the effect of a chemical JA analog on S. enterica persistence and investigated the importance of the bacterial flagellum in this system.

\section{MATERIALS AND METHODS}

\section{Bacterial Strains, Media, and Culture Conditions}

The nalidixic acid-resistant strain of $S$. enterica serovar Typhimurium 14028s (S. Typhimurium; Cowles et al., 2016) was used as wildtype in this study (Table 1). The fliF::Kan mutant was generated using primers listed in Table $\mathbf{2}$ with the $\lambda$ Red recombinase method (Datsenko and Wanner, 2000), and the motA::Kan mutant was obtained from a mutant library collection (Santiviago et al., 2009). These deletion-insertion mutations were transduced into a fresh $S$. Typhimurium background using P22 (Gemski and Stocker, 1967) and confirmed by PCR (see Table 2 for confirmation primers). Bacterial cultures were grown in lysogeny broth (LB) at $37^{\circ} \mathrm{C}$ with shaking at $200 \mathrm{rpm}$. The antibiotics nalidixic acid ( $\mathrm{Nal}$ ) and kanamycin (Kan) were used at concentrations of 20 and $50 \mu \mathrm{g} / \mathrm{ml}$, respectively. Strains used
TABLE 1 | List of strains.

\begin{tabular}{lll}
\hline $\begin{array}{l}\text { Strain } \\
\text { designation }\end{array}$ & Genotype & $\begin{array}{l}\text { Reference } \\
\text { or source }\end{array}$ \\
\hline \multicolumn{2}{c}{ Salmonella enterica strains } & \\
JDB682 & S. enterica serovar Typhimurium 14028s & ATCC \\
JDB1034 & S. enterica serovar Typhimurium 14028s; Nal ${ }^{R}$ & This study \\
JDB903 & $\Delta$ fliF::Kan & This study \\
JDB902 & $\Delta$ motA::Kan & This study \\
\hline
\end{tabular}

in this study are shown in Table $\mathbf{1}$, and primers used to confirm bacterial mutants are shown in Table 2.

\section{Insect Rearing}

A colony of Aster leafhoppers ( $M$. quadrilineatus) was maintained on oat plants (Avena sativa L.) in a controlled environment with a $16 \mathrm{~h}$ photoperiod with $24^{\circ} \mathrm{C}$ light and $19^{\circ} \mathrm{C}$ dark. Even-aged, 3- to 5-day-old adult insects were used for all experiments.

\section{Plant Inoculation and Infestation}

Solanum lycopersicum (tomato) cultivar MoneyMaker seedlings were cultivated in Professional Growing Mix (Sunshine Rediearth) with a $16 \mathrm{~h}$ photoperiod at $24^{\circ} \mathrm{C}$ for 5 weeks. For colonization assays, bacterial cultures were grown overnight in $\mathrm{LB}$ and normalized to an optical density at $600 \mathrm{~nm}\left(\mathrm{OD}_{600}\right)$ of 0.2 in sterile water. $\mathrm{An} \mathrm{OD}_{600}$ of 0.2 corresponds to a bacterial population level of $\sim 10^{8} \mathrm{CFU} / \mathrm{ml}$, and this inoculum level was used for all experiments. Prior to inoculation, 0.025\% Hi-Wett (Loveland Products, Inc.) was added to water or the bacterial inoculum. Pots containing tomato plants were dip-inoculated by inverting plants in either sterile water or the bacterial inoculum for $1 \mathrm{~min}$ with agitation to prevent bacterial cell settlement (Figure 1). Dip-inoculated plants were incubated under the blower in a SterilGARD Class II Biosafety Cabinet (The Baker Company) for $1 \mathrm{~h}$ to dry the leaves. After the 1-h drying period, half of the water-dipped and half of the bacterial-dipped plants were fitted with empty clip cages on two middle leaflets (as defined in Potnis et al., 2014; Figure 1). Clip cages are two cm diameter plexiglass cylinders topped with plastic screen that were attached to the upper leaf surface to trap insects on the leaflet (Figure 1). The remaining dip-inoculated plants were fitted with clip cages containing four adult leafhoppers each. Plants were incubated at high humidity in lidded, plastic bins under grow lights with a $16 \mathrm{~h}$ photoperiod at room temperature $\left(\sim 26^{\circ} \mathrm{C}\right)$. At multiple time points post-inoculation and/or post-infestation, leaf samples were taken from within clip cages using destructive sampling to determine bacterial populations and collect samples for RNA extraction.

\section{Chemical Analog Treatment}

For exogenous induction of the JA response, 5-week-old MoneyMaker tomato seedlings were sprayed with a fine mist of sterile water or methyl jasmonate (MeJA; 0.000001\%; Sigma Aldrich, St. Louis, MO, United States). The MeJA concentration was chosen to most closely mimic the plant response to a 
TABLE 2 | List of primers.

\begin{tabular}{|c|c|c|c|}
\hline \multirow[t]{2}{*}{ Primer } & \multicolumn{2}{|c|}{ Primer sequence $\left(5^{\prime}-3^{\prime}\right)$} & \multirow[t]{2}{*}{$\%$ Efficiency } \\
\hline & Forward & Reverse & \\
\hline \multicolumn{4}{|c|}{ Quantitative PCR analysis $^{a}$} \\
\hline act41 & GCTCTTGACTATGAACAGGAAC & AAGGACCTCAGGACACCG & 104 \\
\hline ubi3 & GCCGACTACAACATCCAGAAGG & TGCAACACAGCGAGCTTAACC & 105 \\
\hline $\operatorname{pin} 1$ & GCTAAGGAAATAATTGAGAAGGA & TAAGTCACCACAGGCATT & 102 \\
\hline pr1a1 & TCAAAGAGCTGATGACTGTG & GTACCATTGCTTCTCATCGT & 102 \\
\hline \multicolumn{4}{|c|}{ Mutant construction and confirmation ${ }^{b}$} \\
\hline fliF::Kan construction & $\begin{array}{c}\text { ATGAGTGCGACTGCATCGACTGC } \\
\text { AACCCAACCTAAACCTCGTGTA } \\
\text { GGCTGGAGCTCCTTC }\end{array}$ & $\begin{array}{l}\text { GATCGTTACTCATCCACTGGCG } \\
\text { AATGACCAGCGCCACC } \\
\text { ACCATATGAATATCCTCCTTAG }\end{array}$ & \\
\hline fliF::Kan confirm & CGTTGCGATGGTGCTGTGGG & GCGCGTCAACTGCGGACGTA & \\
\hline motA::Kan confirm & GCGGACACCTTGGGGCACTC & TGGACGCTCACTGGAATAAAGCG & \\
\hline
\end{tabular}

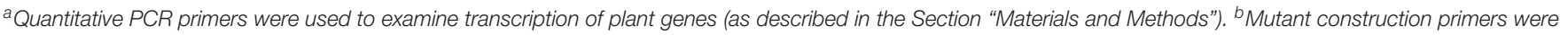

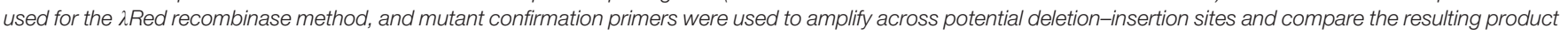
sizes to that observed when using wildtype genomic DNA as a template.

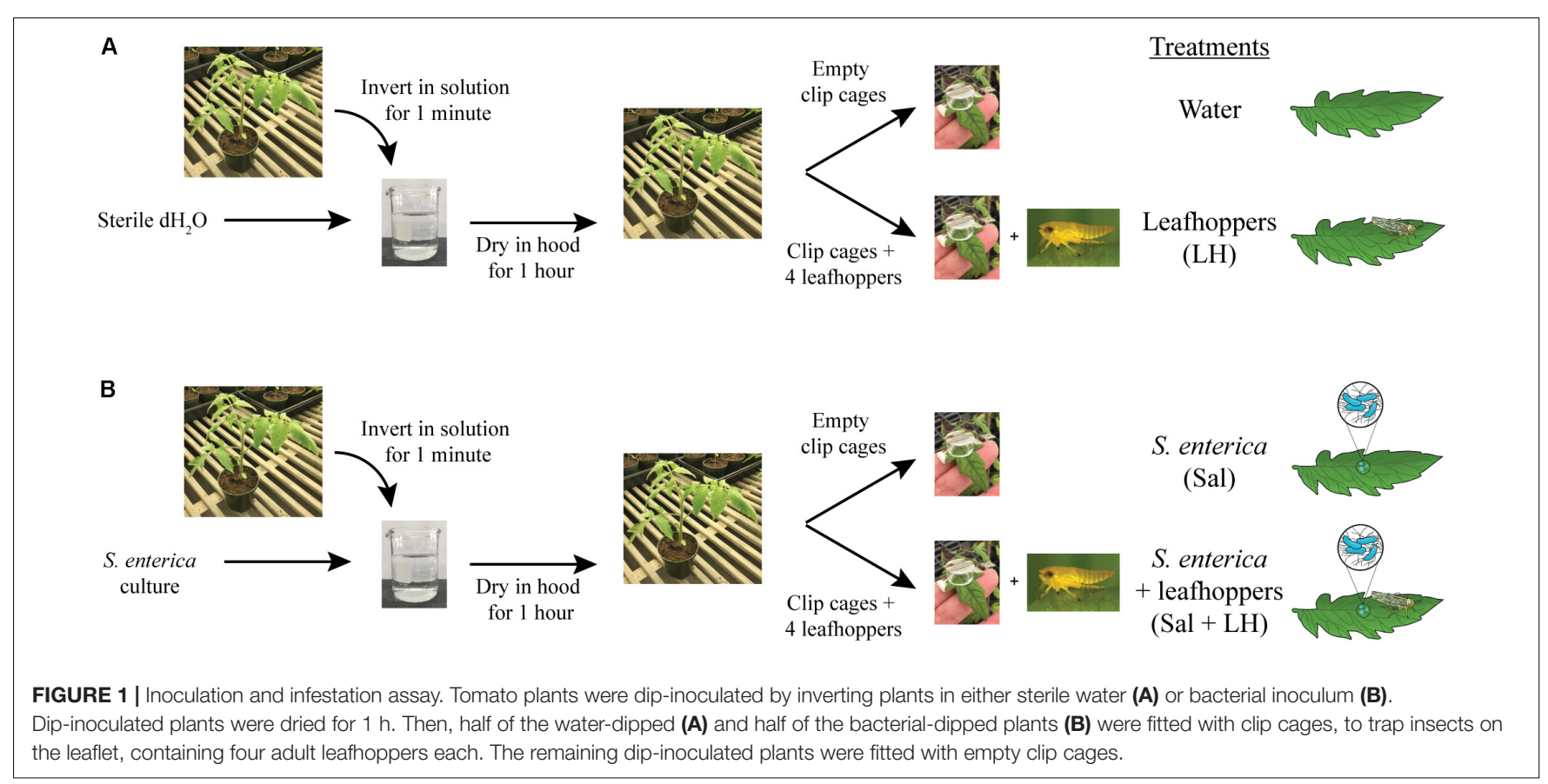

leafhopper infestation; optimization experiments determined that there were no observable changes in plant morphology, and the level of JA induction was similar to that seen in response to the insects (data not shown). Plants were incubated for $24 \mathrm{~h}$ at high humidity and then dip-inoculated in water or bacterial suspension as described above. Dipped plants were incubated at high humidity as described above. At days 0, 3, 6, 10 , and 14 (post-dip inoculation), leaf samples were taken from middle leaflets using destructive sampling to determine bacterial populations and collect samples for RNA extraction.

\section{Bacterial Population Sampling}

At indicated time points, one $79 \mathrm{~mm}^{2}$ leaf disc was taken from each of two leaflets on middle leaves (Potnis et al., 2014). Samples from four plants per treatment per time point were transferred to microfuge tubes and homogenized in $500 \mu \mathrm{l}$ of sterile water using a $4.8 \mathrm{~V}$ rotary tool (Dremel, Mount Prospect, IL, United States) with microcentrifuge tube sample pestle attachment (Thermo Fisher Scientific). Homogenates were diluted 1:10 in sterile water and spiral plated (Autoplate 4000, Spiral Biotech, Norwood, MA, United States) on LB Nal plates. Resulting colonies were counted after overnight incubation at $37^{\circ} \mathrm{C}$ to determine bacterial populations. Experiments were performed with three biological replicates.

\section{RNA Isolation}

At indicated time points, two $79 \mathrm{~mm}^{2}$ leaf discs were taken from each of two leaflets on middle leaves (Potnis et al., 
2014) and combined for a total of four leaf discs per plant. Samples from four plants per treatment per time point were collected and frozen at $-80^{\circ} \mathrm{C}$ for further processing. RNA was extracted using the PureLink RNA Purification kit (Invitrogen) with some modifications. Briefly, four leaf discs were homogenized with a mortar and pestle in the presence of liquid nitrogen. Ground tissue was transferred to a small weigh boat containing $1 \mathrm{ml}$ Trizol, mixed with a pipette tip, and transferred to a microcentrifuge tube. Samples were then processed according to manufacturer's instructions and eluted in $100 \mu \mathrm{l}$ volume of RNase-free water. RNA was treated with Turbo DNA-free (Ambion) for 30 min using the manufacturer's protocol and quantified by NanoDrop (Thermo Fisher Scientific). RNA was isolated from three biological replicates for each experiment.

\section{cDNA Synthesis and Real-Time PCR}

cDNA synthesis was performed using the iScript cDNA synthesis kit according to manufacturer's instructions (Bio-Rad) with $1.5 \mu \mathrm{g}$ total RNA as input. Real-time PCR primers were designed with Beacon Designer software (Premier Biosoft International) avoiding template secondary structure (Table 2). Primer efficiencies (Table 2) were calculated using serial dilutions of MoneyMaker genomic DNA and CFX Manager 3.0 software (Bio-Rad). Reference transcripts were chosen based on published works: act41 and ubi3 (Rotenberg et al., 2006). Stable expression between treatments was validated using the Best Keeper program and four independent RNA samples from each treatment. Real-time PCR experiments were performed as described (Jahn et al., 2008; Cowles et al., 2016). Experiments were performed using the CFX96 Real-Time System and analyzed with the CFX Manager 3.0 software (Bio-Rad). The mean $\mathrm{Cq}$ of each target transcript was normalized by the mean $\mathrm{Cq}$ of each reference gene using the formula: $2^{(-(C q}$ target $-C q$ reference)). As previously described (Rotenberg et al., 2006), we determined the relative expression ratio (RER) of the target gene by dividing the normalized target RNA by a calibrator consisting of the average of the normalized values of the control samples (expression after water treatment in these experiments).

\section{Statistical Analysis}

All statistical analyses were performed using R software (version 2.14.1; R Development Core Team, R Foundation for Statistical Computing, Vienna, Austria ${ }^{1}$ ) as described (Kwan et al., 2015). Briefly, three biological replicates were performed for each experiment, and samples taken from one replicate were considered as subsamples. To determine whether bacterial population results differed between treatments in the leafhopper and chemical analog experiments, analysis of covariance (ANCOVA) was used as previously described (Soto-Arias et al., 2013), with treatment and time as covariates. For real-time PCR analysis, four samples were compared for each treatment at each time point using Tukey's HSD test. Results were considered statistically significant at $P<0.05$.

${ }^{1}$ http://www.R-project.org

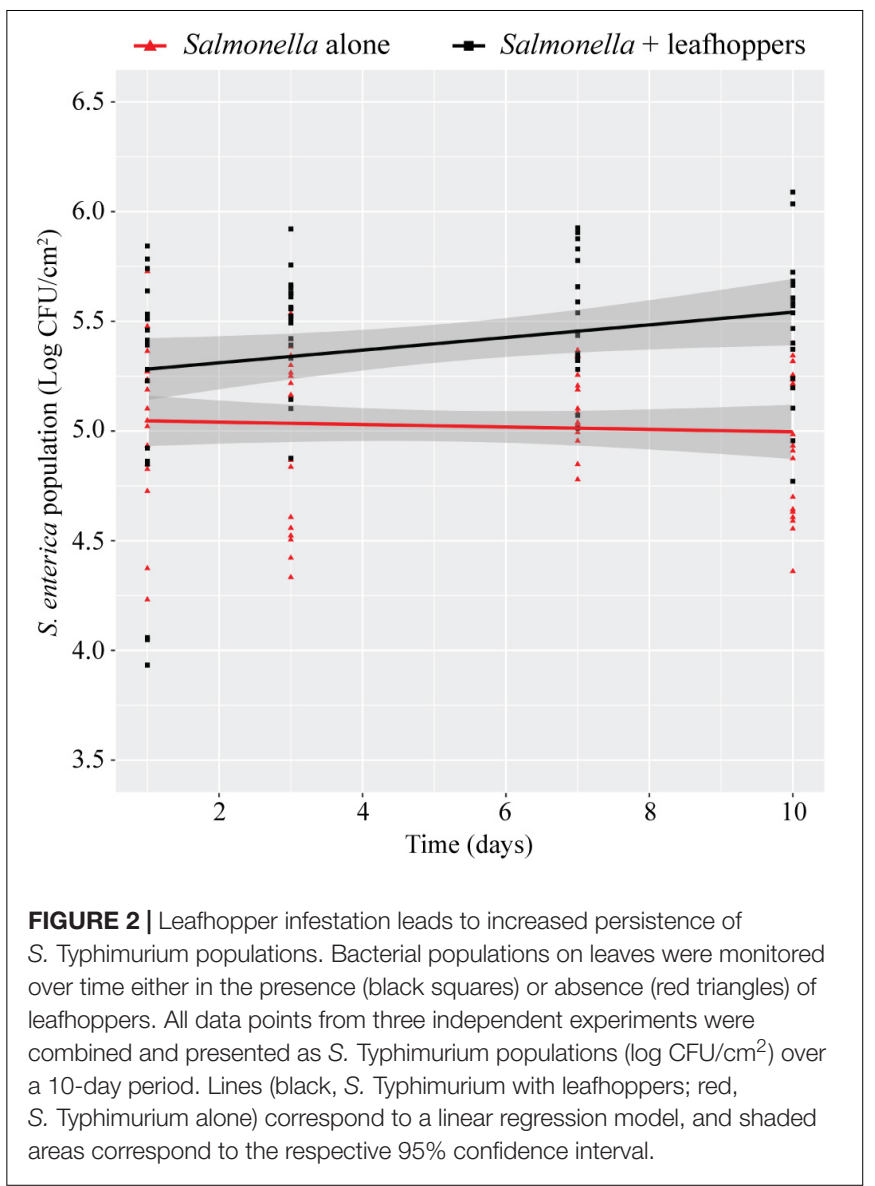

\section{RESULTS}

\section{The Presence of Leafhoppers Enhances S. Typhimurium Persistence on Tomato Leaves}

Previously, we had shown that infestation with phytophagous insects promotes $S$. enterica survival on the leaves of lettuce plants (Soto-Arias et al., 2013). To determine if this effect occurs in additional plant species, bacterial populations were monitored on tomato plants (S. lycopersicum) infested with leafhoppers (Figure 2). The presence of leafhoppers significantly enhanced the persistence of $S$. Typhimurium populations over time compared to plants that were inoculated with bacteria alone (Figure 2). After 10 days, S. Typhimurium populations were approximately $1 / 2 \log$ higher in the presence of leafhoppers than in plants that were not infested with insects (Figure 2).

\section{Co-inoculation of $S$. Typhimurium and Leafhoppers Alters the Plant Immune Response}

To test the hypothesis that insect infestation changes the plant immune response to the benefit of $S$. Typhimurium, plant defense gene expression was monitored over time in tomatoes inoculated with leafhoppers, S. Typhimurium, or a combination 
of leafhoppers and S. Typhimurium. The JA-inducible proteinase inhibitor gene pin1 and the SA-inducible pathogenesis related protein gene prlal were used as established markers (Tornero et al., 1994; Fowler et al., 2009) to monitor the two plant defense responses with quantitative PCR. Day 3 post-inoculation was chosen as the initial time point to monitor plant immune gene expression as it was the time when bacterial populations began to diverge when comparing treatments with or without leafhopper infestation (Figure 2). Compared to the negative control (plants treated with water), tomatoes that were infested with leafhoppers showed a significant induction of pin1 expression and displayed an intermediate level of prlal expression on day 3 post-inoculation (Figures $\mathbf{3 A}, \mathbf{B}$ ). Contrastingly, tomato plants treated with $S$. Typhimurium had no change in pin1 expression compared to the water control, but had a significant induction of prlal expression on day 3 (Figures 3A,B). Plants that were simultaneously treated with both leafhoppers and $S$. Typhimurium responded with an increase in pin1 expression but no significant change in prlal gene expression on day 3 (Figures 3A,B). To examine the impacts on later stages of colonization, plant defense gene expression was also measured at day 6 post-inoculation. By day 6, plants that were treated with both leafhoppers and $S$. Typhimurium induced both pin1 and prlal while treatment with $S$. Typhimurium alone led to an intermediate induction of pin1 expression compared to the water control (Figures 3C,D). By day 6, pin1 and pr1a1 levels were not significantly different from the negative control following leafhopper infestation (Figures 3C,D).

\section{Exogenous Treatment With Methyl Jasmonate Is Sufficient to Increase Bacterial Persistence}

To differentiate the effects of leafhoppers on the plant immune response from other potentially beneficial impacts of insect infestation on $S$. Typhimurium, we artificially induced the JA defense response with exogenous application of a chemical JA analog, MeJA. Due to biosafety limitations when studying $S$. Typhimurium, MeJA treatment was performed $24 \mathrm{~h}$ prior to bacterial dip-inoculation instead of concurrently as done in experiments with leafhoppers (Figure 1). Leaves sprayed with MeJA displayed an induction of pin1 expression that was comparable to the leafhopper-induced JA response (Figure 3) and lasted through day 6 post-bacterial inoculation (Figures 4A, 5A). MeJA treatment led to a significant increase in $S$. Typhimurium population persistence compared to negative control plants that were sprayed with sterile water (Figure 4B).

\section{The Bacterial Flagellum Is Necessary for Enhanced S. Typhimurium Persistence After MeJA Treatment}

To identify bacterial factors that impact the connection between $S$. Typhimurium persistence and the immune response, we examined bacterial populations in two motility mutants: $f l i F:$ Kan and motA::Kan. As motility has previously been linked to bacterial persistence on plant leaves (Haefele and Lindow, 1987; Lindow et al., 1993) and the S. enterica flagellum is a known stimulus of the plant immune response (Garcia et al., 2014), we hypothesized that the flagellum may play a role in bacterial persistence in our experimental system. The fliF gene encodes the inner membrane ring required for construction of the bacterial flagellum, and $\operatorname{mot} A$ encodes one of the membrane proteins that acts as a stator in the flagellar motor (Block and Berg, 1984; Homma et al., 1987a,b; Blair and Berg, 1990). Although both mutants are non-motile, the fliF::Kan mutant does not make a flagellum while the motA::Kan mutant makes a nonfunctional flagellum (Block and Berg, 1984; Homma et al., 1987a,b; Blair and Berg, 1990). Plants were treated with MeJA (as described above) and then dip-inoculated with either wildtype, the $f l i F:$ Kan mutant, or the motA::Kan mutant. While MeJA treatment resulted in a significant increase in the persistence of wildtype $S$. Typhimurium, populations of the fliF::Kan mutant were not significantly different on plants treated with MeJA or water (Figure 4B). Examination of pin1 expression revealed that JA induction did not persist as long in plants inoculated with the $f l F:$ Kan mutant compared to wildtype (Figures 4A,C). Unlike the fliF::Kan mutant, MeJA enhanced persistence of the motA::Kan mutant compared to the water control (Figure 5B), and JA induction continued through day 6 after inoculation for the motA::Kan mutant (Figure 5C). To further characterize the effects of these treatments on plant immunity, we also monitored transcription of the SA response using pr1a1 primers (Figure 6). Expression of prlal was significantly induced after MeJA treatment and bacterial dip-inoculation in all tested strains at variable time points (Figure 6).

\section{DISCUSSION}

Although best characterized for its role as a human enteric pathogen, S. enterica colonizes plants as part of its lifecycle and as a means for returning to an animal host (for review, see Barak and Schroeder, 2012). Although S. enterica cannot disrupt plant cells such as plant pathogens to release nutrients from the leaf surface, the bacteria successfully survive in the plant environment and persist for months with a slow decline in populations over time (Islam et al., 2004a,b). Biomultipliers, such as phytobacterial pathogens or phytophagous insects, enhance $S$. enterica survival by altering the plant environment to the benefit of the enteric pathogen (Kwan et al., 2013; Soto-Arias et al., 2013; Potnis et al., 2014, 2015). Understanding the mechanisms for the interaction between $S$. enterica and these biomultipliers is important in order to reduce the risk of human disease from contaminated produce. In this study, we describe how phytophagous insects modulate plant immunity, and further, we provide a mechanism linking the bacterial flagellum and the plant JA response to $S$. enterica persistence.

Here, we examined the impact of one common phytophagous insect, the Aster leafhopper, and further characterized its role as a biomultiplier of $S$. Typhimurium populations. Using a similar methodology as described in this study (Figure 1), we had previously shown that leafhoppers enhance S. enterica persistence on lettuce plants (Soto-Arias et al., 2013). Those experiments demonstrated that, regardless of treatment, 

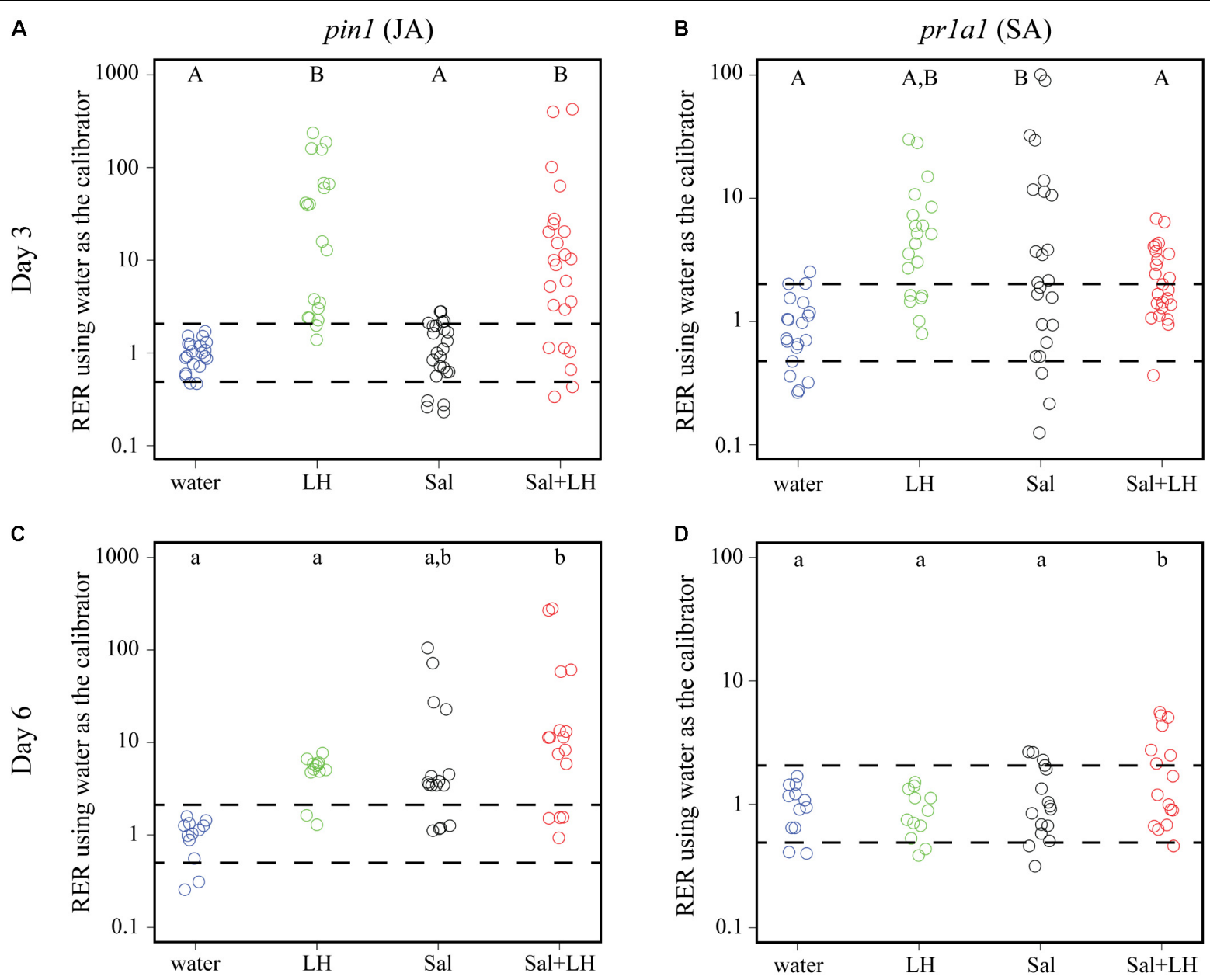

FIGURE 3 | Transcription of plant defense genes changes in response to leafhoppers (LH; green circles), S. Typhimurium bacteria (Sal; black circles), or co-inoculation of bacteria with leafhoppers (Sal+LH; red circles). Plant gene expression was quantified at days 3 (A,B) and 6 (C,D) post-inoculation. Data for the JA-inducible pin1 $(\mathbf{A}, \mathbf{C})$ and SA-inducible pr1a1 (B,D) are displayed as relative expression ratios (RER) using transcription in plants treated with water (blue circles) as the negative control and calibrator. The dashed line indicates a twofold change in transcription, and each circle represents data collected from one tomato plant. Transcript levels were quantified from three biological replicates with samples taken from at least four plants per treatment per time point. Letters denote significant differences between treatments within a single time point for that specific plant defense gene $(P<0.05)$.

S. enterica populations slowly decline over time. Infestation with leafhoppers increased the longevity of a cocktail of $S$. enterica strains (Cubana, Enteritidis, Newport, Poona, Schwarzengrund, Baildon, and Mbandaka) on lettuce leaves compared to plants without insect infestation (Soto-Arias et al., 2013). In this study, we demonstrate that, in the absence of leafhoppers, $S$. Typhimurium populations on tomato leaves also show a slow decline (Figure 2). However, two noticeable differences can be observed when comparing the data from lettuce to those collected from tomato. First, in the absence of leafhoppers, the decline in $S$. Typhimurium populations on tomato leaves appears to be slower (Figure 2) than the decline that was observed on lettuce (Soto-Arias et al., 2013). Second, in contrast to the experiments performed with lettuce (Soto-Arias et al., 2013), leafhopper infestation on tomato plants led to a constant $S$. Typhimurium population with no appreciable loss of overall numbers over the course of the experiment (Figure 2). The maintenance of a steady bacterial population level indicates that either the bacteria remain viable with no significant growth, or bacterial replication rates are equivalent to bacterial death, leading to no observable changes in overall bacterial numbers. The differences observed between bacterial populations on these two plants could also reflect differences in leafhopper feeding behavior on the two plant hosts. Aster leafhoppers overwinter on grains but will infest vegetable crops such as carrot, celery, potato, radish, and lettuce during the growing season (Hagel et al., 1973; Beanland et al., 2005). Although the leafhoppers utilize many different crops as sources of food or refuge, leafhopper reproduction consistently occurs only on lettuce, suggesting lettuce is a more preferred plant host. Thus, on lettuce, the leafhoppers may locate feeding sites quickly and create fewer damage sites (e.g. salivary sheaths) (Miles, 1972; Backus, 1988). Contrastingly, tomato plants, a Solanaceae plant like potato, could be considered a non-preferred host plant for the insects, and the leafhoppers may spend more time probing 
A

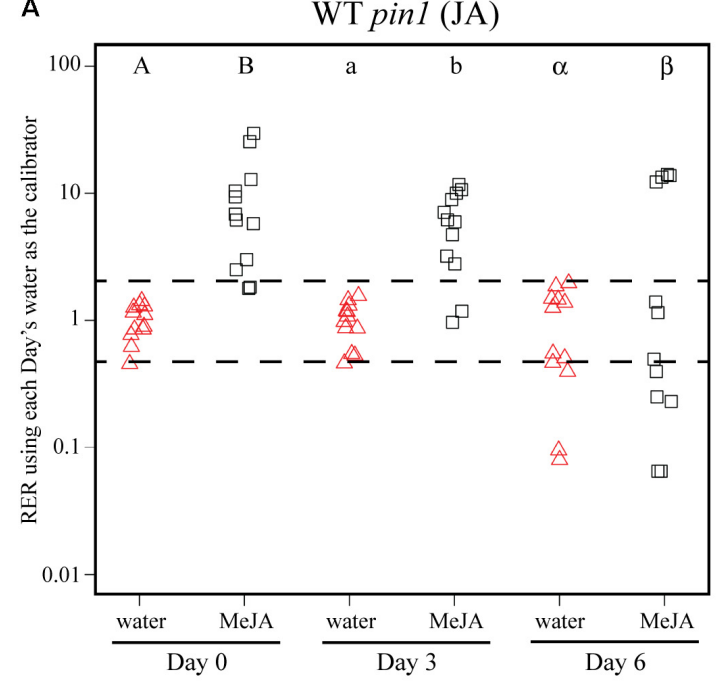

C

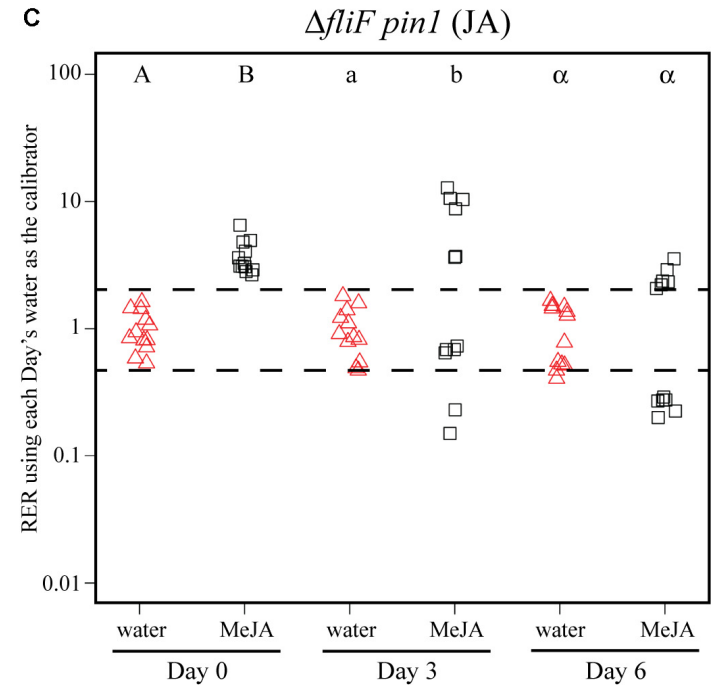

\section{B}

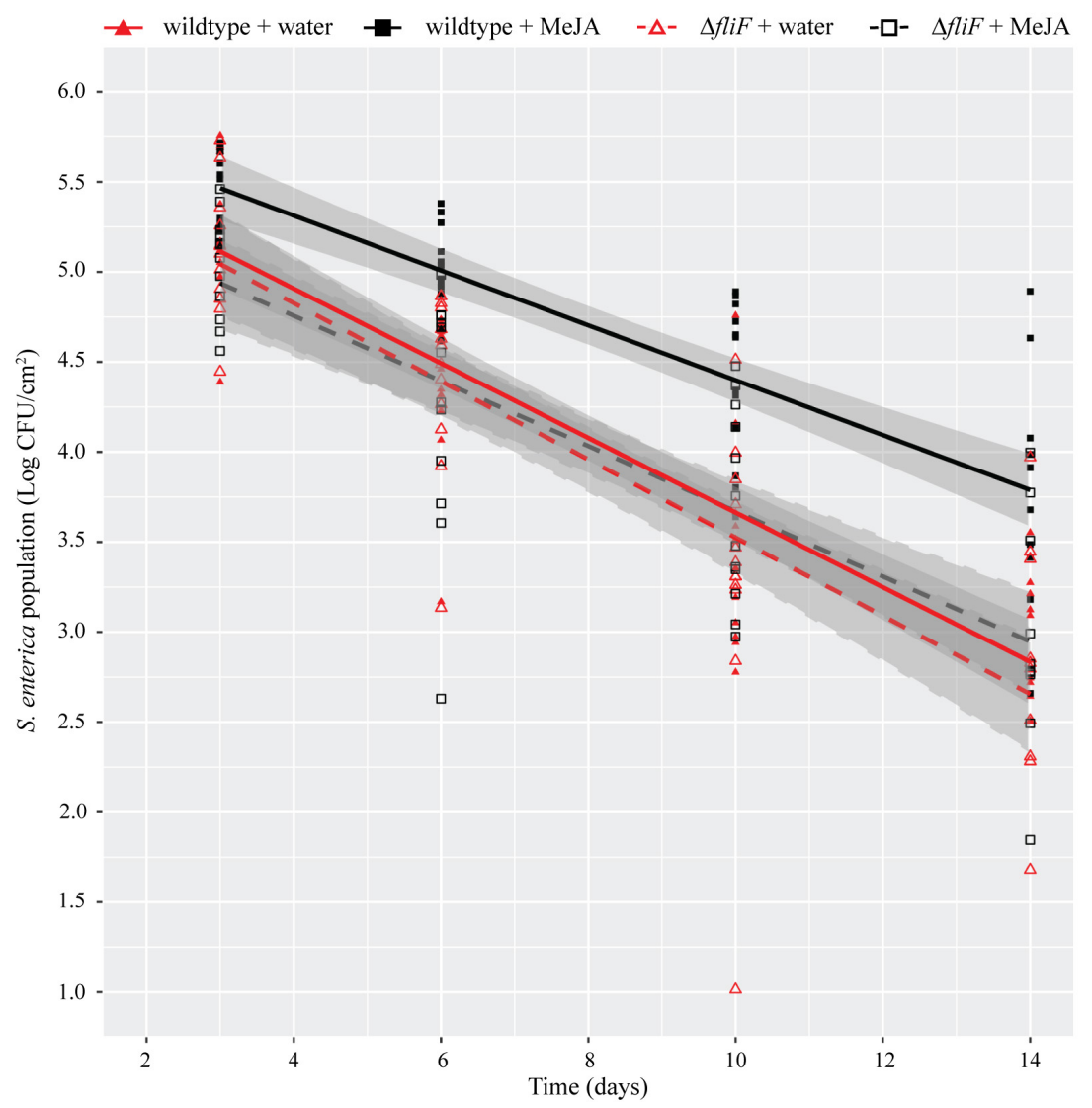

FIGURE 4 | Induction of the JA response with a chemical analog increases S. Typhimurium survival over time. (A,C) Plant pin1 gene expression was quantified at days 0,3 , and 6 post-inoculation with wildtype $S$. Typhimurium (A) or the fliF::Kan mutant (C) for plants sprayed with water (red triangles) or methyl jasmonate (MeJA; black squares) and displayed as relative expression ratios (RER) using transcription on plants treated with water as the calibrator. The dashed line indicates a twofold change in transcription, and each symbol represents data collected from one tomato plant. Transcript levels were quantified from three biological replicates with samples taken from four plants per treatment per time point. Letters denote significant differences between treatments within a single time point $(P<0.05)$.

(B) Bacterial populations on leaves were monitored over time following either treatment with water (red triangles) or MeJA (black squares) $24 \mathrm{~h}$ prior to bacterial dip inoculation. All data points from three independent experiments were combined and presented as S. Typhimurium populations (log CFU/ $\left.\mathrm{cm}^{2}\right)$ over a 14-day period. Lines (red, solid: wildtype S. enterica after water treatment; black, solid: wildtype S. Typhimurium after MeJA treatment; red, dashed: fliF::Kan after water treatment; black, dashed: fliF::Kan after MeJA treatment) correspond to a linear regression model, and shaded areas correspond to the respective $95 \%$ confidence interval. 

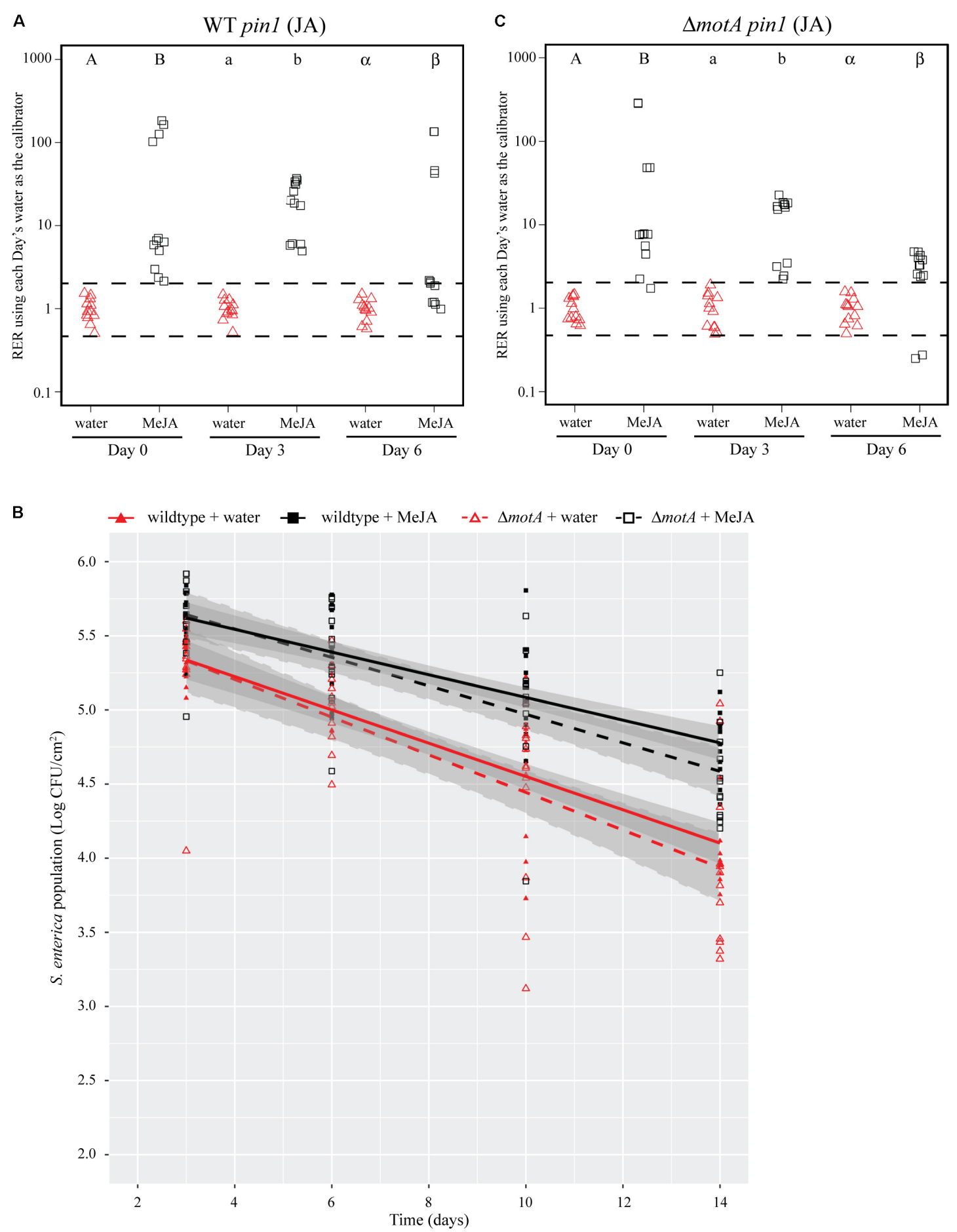

FIGURE 5 | Induction of the JA response with a chemical analog increases S. Typhimurium survival over time. (A,C) Plant pin1 gene expression was quantified at days 0,3 , and 6 post-inoculation with wildtype S. Typhimurium (A) or the motA::Kan mutant (C) for plants sprayed with water (red triangles) or MeJA (black squares) and displayed as relative expression ratios (RER) using transcription on plants treated with water as the calibrator. The dashed line indicates a twofold change in transcription, and each symbol represents data collected from one tomato plant. Transcript levels were quantified from three biological replicates with samples taken from four plants per treatment per time point. Letters denote significant differences between treatments within a single time point $(P<0.05)$. (B) Bacterial populations on leaves were monitored over time following either treatment with water (red triangles) or MeJA (black squares) $24 \mathrm{~h}$ prior to bacterial dip inoculation. All data points from three independent experiments were combined and presented as S. Typhimurium populations (log CFU/cm²) over a 14-day period. Lines (red, solid: wildtype S. Typhimurium after water treatment; black, solid: wildtype S. Typhimurium after MeJA treatment; red, dashed: motA::Kan after water treatment; black, dashed: motA::Kan after MeJA treatment) correspond to a linear regression model, and shaded areas correspond to the respective 95\% confidence interval. 

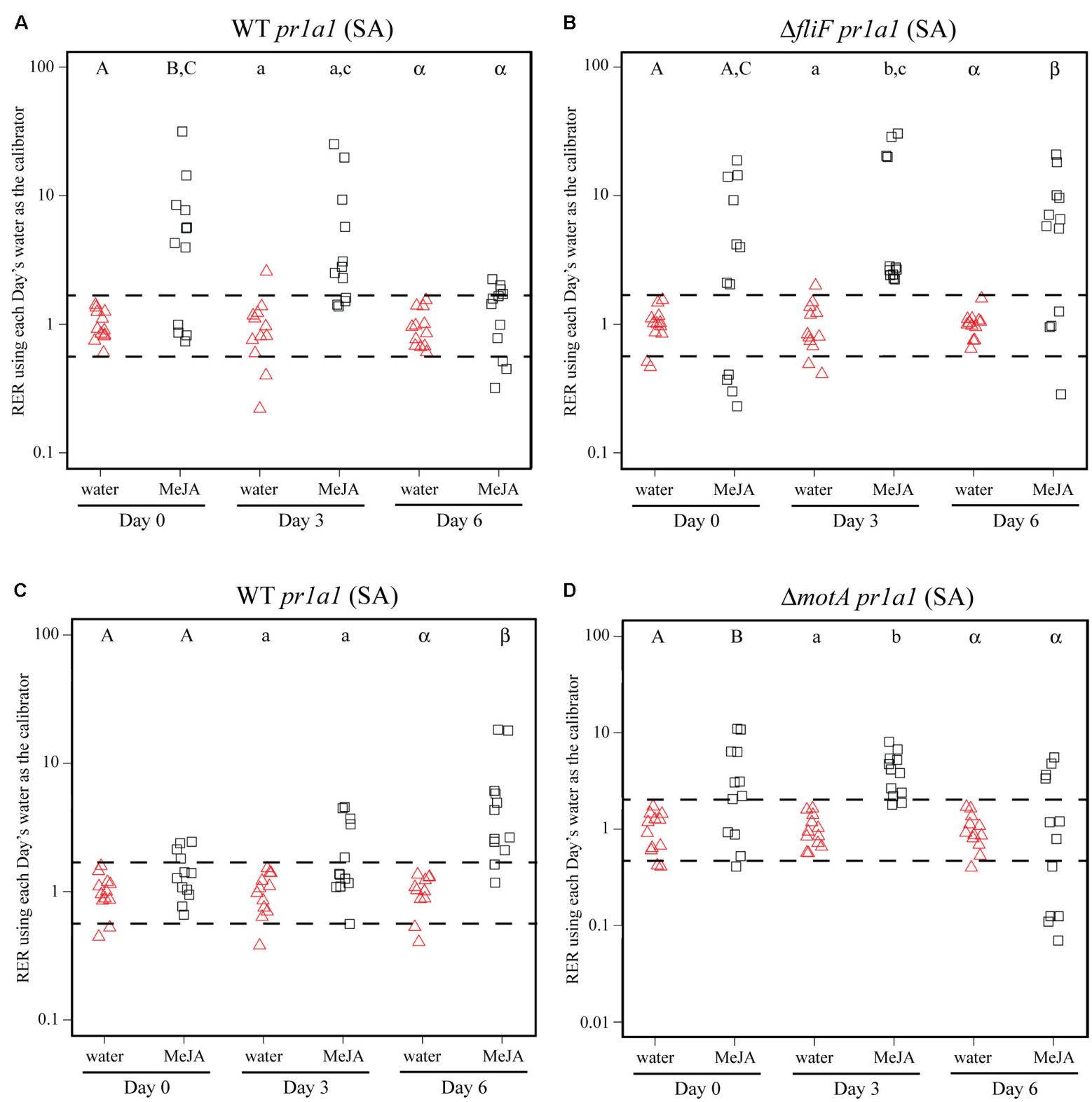

FIGURE 6 | MeJA treatment and S. Typhimurium inoculation lead to activation of the SA response. Plant pr1a1 gene expression was quantified at days 0 , 3, and 6 post-inoculation with wildtype S. Typhimurium (WT; A,C), the fliF::Kan mutant (B) or the motA::Kan mutant (D) for plants sprayed with water (red triangles) or MeJA (black squares) and displayed as relative expression ratios (RER) using transcription on plants treated with water as the calibrator. The fliF::Kan and motA::Kan mutants were tested in separate experiments, and the corresponding wildtype data are displayed for each experiment. The dashed line indicates a twofold change in transcription, and each symbol represents data collected from one tomato plant. Transcript levels were quantified from three biological replicates with samples taken from four plants per treatment per time point. Letters denote significant differences between treatments within a single time point in each experiment $(P<0.05)$.

the plant in search of nutrients. The increased probing has the potential to increase the defense response. Although we do not have data from lettuce as a comparison, we observed a robust induction of the JA response (12- to 236-fold) after 3 days of leafhopper infestation (Figure 3A). Interestingly, by 6 days postinfestation, pin 1 levels were not significantly different between water-treated plants and leafhopper-treated plants (Figure 3C). This reduction in the JA response over time may suggest that leafhoppers stop feeding at later points in the experiment and may be further evidence that tomato are not a preferred food source. Future experiments could address these questions by examining the lettuce defense responses in comparison to the tomato response presented here and monitoring leafhopper feeding patterns using these plant systems.

We hypothesize that leafhopper-induced alterations to plant immunity provide a benefit to $S$. Typhimurium and extend bacterial survival on the leaf surface. By day 3 post-inoculation, co-inoculation of leafhoppers with $S$. Typhimurium led to a 
significant induction of the JA response while there was no change in the SA response until day 6 (Figure 3). Due to the strong, sustained induction of pin 1 expression, we chose to focus on the role of the JA response in enhancing $S$. Typhimurium persistence. To determine if changes in the JA response are sufficient for the effects on bacterial persistence, plants were treated with the analog MeJA to activate the immune response in the absence of leafhoppers. If MeJA treatment provided the same advantage as leafhopper infestation for $S$. Typhimurium populations, then we could rule out other mechanisms that explain the effect that leafhoppers have on bacterial populations, such as providing increased nutrients during insect feeding. Our results demonstrate that MeJA treatment enhanced bacterial persistence (Figure $\mathbf{4 B}$ ), indicating that induction of the JA response is involved in the effect on bacterial populations. Contrasting to the leafhopper experiments (Figure 2), S. Typhimurium populations continued to decline over time after MeJA treatment (Figure 4B). As discussed above, leafhopper infestation resulted in a flat slope for the linear regression line describing bacterial populations while mock-treated plants had slowly declining levels of $S$. Typhimurium (Figure 2). In the MeJA experiments, we observed that both the watertreated and the MeJA-treated plants had a sharper decline in $S$. Typhimurium populations compared to the leafhopper experiment (Figures 4,5 compared to Figure 2). Statistical analyses indicate that we cannot attribute the differences in slopes to the different experimental procedures used for these experiments. In the MeJA experiments, plants were sprayed with water or MeJA $24 \mathrm{~h}$ prior to bacterial inoculation while this treatment was not used in the leafhopper experiment. We found that bacterial populations on water-treated plants from the leafhopper experiment (Figure 2) were not significantly different from populations on water-treated plants in the MeJA motA::Kan experiment (Figure 5) at days 3, 6, and 7 but both populations were statistically different than those seen on water-treated plants in the MeJA fliF::Kan experiment (Figure 4) on those days $(P<0.05)$. The leafhopper experiment data (Figure 2) were statistically different from both MeJA experiments (Figures 4, 5) by day $10(P<0.05)$. Biological variability does not explain these results as biological replicates within each experiment (each figure represents three independent experiments for those treatments) were not significantly different from one another $(P>0.05)$. This statistical analysis does preclude any conclusions that can be made about the sufficiency of JA induction on bacterial population enhancement. However, whole genome transcriptome analyses examining the plant response to insect herbivory demonstrate that plants alter transcription in multiple pathways, including primary metabolism, signaling, cell wall modification, and oxidative stress (Schwachtje and Baldwin, 2008; Kerchev et al., 2012). In the face of such a widespread response, we would have been surprised to find that JA induction alone was sufficient to effect bacterial persistence. Thus, although induction of the JA response (by leafhopper infestation or MeJA treatment) provides a benefit to $S$. Typhimurium, we hypothesize that additional mechanisms are likely present that also affect bacterial survival. When leafhoppers feed on leaves, they must excrete excess carbohydrates to counterbalance the difference in osmolarity that they encounter in the phloem (Wilkinson et al., 1997). These excretions are termed "honeydew," and we have data showing that $S$. enterica can use honeydew as a nutrient source (J. Dundore-Arias, personal communication). Release of nutrients from the leaf during leafhopper feeding or excretion of honeydew by the insects could provide a nutrient source for S. enterica in the otherwise nutrient poor environment on the leaf surface. Utilization of insect byproducts has been described for other human enteric pathogens as regurgitation by house flies provides nutrients for pathogenic Escherichia coli and leads to bacterial replication on spinach leaves (Wasala et al., 2013). Future analysis of honeydew as a nutrient source for S. enterica and quantification of leafhopper excretions on the leaf surface will elucidate the impact of nutrient availability on S. enterica survival.

The data presented in this study demonstrate that the presence of leafhoppers alter hormone production (Figure 3). Alone, $S$. Typhimurium induces the SA response; tomato plants that are inoculated with $S$. Typhimurium and infested with leafhoppers activate both the JA and SA pathways. Similarly, MeJA induction of the JA response in conjunction with $S$. Typhimurium inoculation leads to activation of both the JA and SA pathways (Figures 4-6). In many cases, activation of one pathway suppressors activation of the other pathway (PenaCortes et al., 1993; van Wees et al., 2000; Spoel, 2003; Van der Does et al., 2013; Wei et al., 2014). In nature, plants are often invaded by multiple pests at the same time. The antagonism between the SA and JA pathways allows the plant to prioritize one pathway over the other to provide the most effective response to its attackers (Kunkel and Brooks, 2002; Beckers and Spoel, 2006; Koornneef and Pieterse, 2008). Despite much work describing the antagonistic nature of the SA and JA pathways, it is now accepted that the story is more complicated than the simple model where one pathway is activated while the other pathway is inhibited. For example, evidence from A. thaliana shows that treatment with low concentrations of the two hormones transcriptionally activates both defense pathways while higher concentrations produce the more typical antagonistic effect (Mur et al., 2006). Thus, the relationship between the SA and JA defense responses is dependent on the relative concentration of each hormone and also may be specific to the organism that initially stimulates the response. The data from this study suggest that simultaneous introduction of a phytophagous insect and a bacterium leads to a synergy between the SA and JA pathways. One limitation of this work is the localized nature of the sampling technique. In the leafhopper experiment (Figures 2, 3), leaf samples for bacterial population and RNA analyses were taken from the localized insect infestation site within clip cages. Although the plant immune response initially responds in a localized manner, the plant prepares for further pathogen invasion in a systemic fashion (for review, see Henry et al., 2013). Immune activation leads to induction of the systemic acquired resistance in distal leaves and often includes accumulation of plant hormones like SA. To expand on our understanding, future studies examining the systemic response to these experimental conditions could reveal more information regarding the potential synergistic effects of the SA and JA response in this system. 

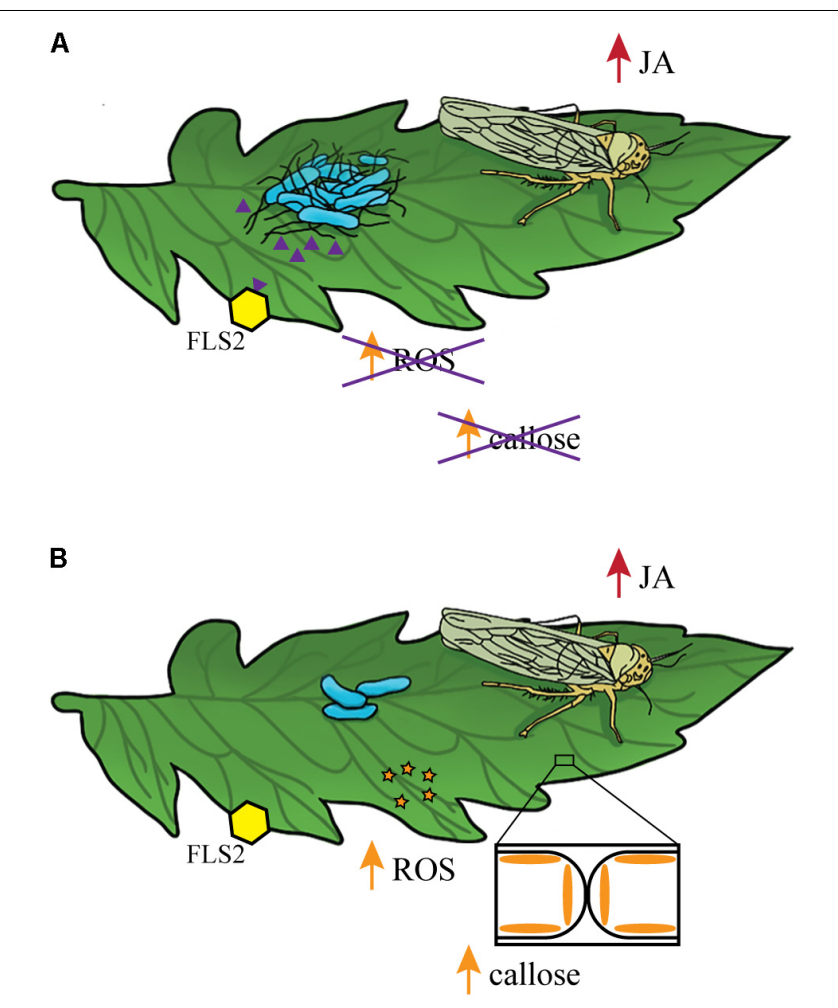

FIGURE 7 | Model describing the link between the bacterial flagellum and the positive effects of leafhopper infestation on $S$. Typhimurium persistence. (A) Leafhopper infestation leads to increased populations of flagellated S. Typhimurium (blue) on the leaf surface. Leafhopper-induction of the JA response (red) in combination with recognition of extracellular S. Typhimurium flg22 peptides (purple triangles) by FLS2 (yellow hexagon) inhibit ROS activation and callose deposition. (B) Although leafhoppers induce the JA response (red), non-flagellated $S$. Typhimurium populations (blue) decline due to activation of ROS activation (orange stars) and callose deposition.

To further define the mechanisms that enhance bacterial survival, we examined the importance of the flagellum, with known roles in motility and immune recognition, in bacterial persistence on tomato leaves. For these experiments, we characterized two mutants with defects in structural or functional aspects of flagellar-based motility. The non-flagellated $f l i F:$ Kan mutant is not motile and does not secrete the immunostimulatory flagellin subunit while the motA::Kan mutant produces an intact flagellum but is not motile due to a non-functional flagellar motor (Block and Berg, 1984; Homma et al., 1987a,b; Blair and Berg, 1990). Although non-motile, the motA::Kan mutant could use the non-functional flagellum for attachment, or the presence of extracellular flagellin monomers in the mutant strain could stimulate an immune response. The difference in the two mutant strains provides a distinction between a requirement for motility ( $f$ liF::Kan) and a requirement for the presence of the flagellum for attachment or stimulation of an immune response (motA::Kan). After pretreatment with MeJA to induce the JA response, the motA::Kan mutant displayed an increase in bacterial persistence (Figure 5B) while the fliF::Kan mutant populations were not significantly different on plants treated with MeJA or water (Figure 4B). The $m o t A::$ Kan results indicate that motility is not required for $S$. Typhimurium to benefit from the MeJA-induced JA response as both the wildtype and non-motile $\operatorname{mot} A:$ Kan strain have enhanced persistence after MeJA treatment. The fliF::Kan data suggest that the presence of the flagellum is needed to enhance bacterial persistence, perhaps through a mechanism involving attachment or recognition by the immune system. We predict that a connection to the immune response is more likely due to evidence that $S$. Typhimurium can attach to plant leaves in a flagellum-independent manner (Berger et al., 2009). Previous work demonstrated that, although a $S$. enterica serovar Senftenberg flagellum mutant has reduced attachment to basil leaves, $S$. Typhimurium (the serovar used in this study) can attach to leaves even in the absence of the flagellum (Berger et al., 2009). Thus, we hypothesize that the effects on immune recognition are a more likely mechanism to explain the role of flagella in this system.

The best characterized bacterial PAMP is the flagellin peptide flg22. This conserved N-terminal region of the flagellin protein is present in both $S$. Typhimurium flagellin proteins FliC and FljB (Garcia et al., 2014) and is recognized by the PRR flagellinsensing protein 2 (FLS2). FLS2 recognition activates a cascade of responses categorized as pathogen-triggered immunity (PTI) (for review, see Melotto et al., 2014). A second PRR FLS3 was recently identified in tomato that recognizes a distinct region of flagellin called flgII-28 (Hind et al., 2016). Previous work in A. thaliana demonstrated that activation of the JA and SA pathways can influence PTI (Yi et al., 2014). Treatment with the flg22 peptide led to SA accumulation, increased ROS production, and increased callose deposition (Meng et al., 2013; Garcia et al., 2014). However, pretreatment with hormone analogs such as the JA mimics coronatine (COR) and MeJA led to a reduction in flg22-induced activation of ROS and callose accumulation (Yi et al., 2014). These results indicate that when the JA response is activated, flg22-induced responses are reduced. However, pretreatment with hormone analogs in the absence of flg22 has no effect on ROS production or callose deposition (Yi et al., 2014). The interaction between the JA response and flg22-induced changes in immunity could explain why wildtype $S$. Typhimurium and the motA::Kan mutant benefit from MeJA induction of the JA pathway while the fliF::Kan mutant does not (for model, see Figure 7). We chose not to include the $\mathrm{SA}$ response in our model because, although it is also activated under these conditions, there were no significant differences in prla1 activation between wildtype and the $f l F:$ Kan mutant (Figure 6), indicating that the SA pathway is not likely to be responsible for the population differences observed for these strains. When inoculated alone, S. enterica flg22 stimulates the immune response which rapidly produces increased levels of ROS and callose deposition (Garcia et al., 2014). Pretreatment with MeJA or infestation with leafhoppers in conjunction with $S$. Typhimurium inoculation activates the JA response (Figures 3-5). Thus, we predict that inoculation with wildtype or the motA mutant, which both produce the flg22 peptide, would lead to a reduction in ROS levels and callose deposition (Figure 7). Inoculation with the fliF mutant, which does not 
make extracellular flagellin, would result in normal levels of ROS activation and callose deposition in response to immune activation (Figure 7). These differential immune responses could explain the differences in bacterial persistence that were observed in the MeJA experiments between the wildtype, motA::Kan mutant, and fliF::Kan mutant (Figures 4, 5). Without flagella, the fliF::Kan mutant must still contend with ROS activation and callose deposition, and induction of the JA pathway is irrelevant to bacterial persistence in the absence of the flagellin protein. Future experiments looking at these downstream outputs of JA- and flg22-induced activation of the immune response could further elucidate the mechanism that leads to enhancement of S. enterica persistence.

In summary, this work provides several important contributions to the study of human enteric pathogens in plant hosts. We present another example of a synergistic response between the SA and JA immune pathways that adds to a growing body of work that challenges the dogma of a strictly antagonistic interaction between these two pathways. Further, we define a potential mechanism by which phytophagous insects enhance human enteric pathogen survival on leaves (Figure 7). Our data suggest that leafhopper-induced activation of the JA response in conjunction with plant responses to flg22 benefit $S$. enterica survival while also providing evidence that suggests additional mechanisms may remain to be discovered. We have advanced the fundamental knowledge describing how the phyllosphere community is influenced by insect herbivory and filled in gaps

\section{REFERENCES}

Backus, E. A. (1988). Sensory systems and behaviours which mediate hemipteran plant-feeding: a taxonomic overview. J. Insect Physiol. 34, 151-165.

Barak, J. D., Kramer, L. C., and Hao, L. Y. (2011). Colonization of tomato plants by Salmonella enterica is cultivar dependent, and type 1 trichomes are preferred colonization sites. Appl. Environ. Microbiol. 77, 498-504. doi: 10.1128/AEM. 01661-10

Barak, J. D., and Liang, A. S. (2008). Role of soil, crop debris, and a plant pathogen in Salmonella enterica contamination of tomato plants. PLoS One 3:e1657. doi: 10.1371/journal.pone.0001657

Barak, J. D., and Schroeder, B. K. (2012). Interrelationships of food safety and plant pathology: the life cycle of human pathogens on plants. Annu. Rev. Phytopathol. 50, 241-266. doi: 10.1146/annurev-phyto-081211-172936

Beanland, L., Madden, L. V., Hoy, C. W., Miller, S. A., and Nault, L. R. (2005). Temporal distribution of aster leafhopper sex ratios and spatial pattern of aster yellows phytoplasma disease in lettuce. Ann. Entomol. Soc. Am. 98, 756-762.

Beckers, G. J., and Spoel, S. H. (2006). Fine-tuning plant defence signalling: salicylate versus jasmonate. Plant Biol. 8, 1-10. doi: 10.1055/s-2005872705

Berger, C. N., Shaw, R. K., Brown, D. J., Mather, H., Clare, S., Dougan, G., et al. (2009). Interaction of Salmonella enterica with basil and other salad leaves. ISME J. 3, 261-265. doi: 10.1038/ismej.2008.95

Blair, D. F., and Berg, H. C. (1990). The MotA protein of E. coli is a protonconducting component of the flagellar motor. Cell 60, 439-449.

Block, S. M., and Berg, H. C. (1984). Successive incorporation of force-generating units in the bacterial rotary motor. Nature 309, 470-472.

Centers for Disease Control and Prevention (2005). Outbreaks of Salmonella infections associated with eating Roma tomatoes-United States and Canada, 2004. MMWR Morb. Mortal. Wkly. Rep. 54, 325-328.

Centers for Disease Control and Prevention (2007). Multistate outbreaks of Salmonella infections associated with raw tomatoes eaten in restaurantsUnited States, 2005-2006. MMWR Morb. Mortal. Wkly. Rep. 56, 909-911. in understanding the biology of tri-tropic interactions between an enteric human pathogen, a phytophagous insect, and a plant host.

\section{AUTHOR CONTRIBUTIONS}

$\mathrm{KC}, \mathrm{RG}$, and JB conceived the study, analyzed the data, and wrote the manuscript. KC conducted the assays. All authors have read and approved the final manuscript.

\section{FUNDING}

Funding was provided by USDA-NIFA 2016-67017-24422 and the Food Research Institute at the University of WisconsinMadison. The funders had no role in study design, data collection and interpretation, or the decision to submit the work for publication.

\section{ACKNOWLEDGMENTS}

We would like to thank Victoria Lason for drawing the cartoons of leafhoppers, bacteria, and leaves used in Figures 1, 6, Caitilyn Allen for providing primer sequences for pr1a1, and JB's lab members for helpful discussions.

Chung, S. H., Rosa, C., Hoover, K., Luthe, D. S., and Felton, G. W. (2013a). Colorado potato beetle manipulates plant defenses in local and systemic leaves. Plant Signal. Behav. 8:e27592. doi: 10.4161/psb.27592

Chung, S. H., Rosa, C., Scully, E. D., Peiffer, M., Tooker, J. F., Hoover, K., et al. (2013b). Herbivore exploits orally secreted bacteria to suppress plant defenses. Proc. Natl. Acad. Sci. U.S.A. 110, 15728-15733. doi: 10.1073/pnas.1308867110

Cowles, K. N., Willis, D. K., Engel, T. N., Jones, J. B., and Barak, J. D. (2016). Diguanylate cyclases AdrA and STM1987 regulate Salmonella enterica exopolysaccharide production during plant colonization in an environmentdependent manner. Appl. Environ. Microbiol. 82, 1237-1248. doi: 10.1128/ AEM.03475-15

Cummings, K., Barrett, E., Mohle-Boetani, J. C., Brooks, J. T., Farrar, J., Hunt, T., et al. (2001). A multistate outbreak of Salmonella enterica serotype Baildon associated with domestic raw tomatoes. Emerg. Infect. Dis. 7, 1046-1048. doi: 10.3201/eid0706.010625

Datsenko, K. A., and Wanner, B. L. (2000). One-step inactivation of chromosomal genes in Escherichia coli K-12 using PCR products. Proc. Natl. Acad. Sci. U.S.A. 97, 6640-6645.

Fowler, J. H., Narvaez-Vasquez, J., Aromdee, D. N., Pautot, V., Holzer, F. M., and Walling, L. L. (2009). Leucine aminopeptidase regulates defense and wound signaling in tomato downstream of jasmonic acid. Plant Cell 21, 1239-1251. doi: 10.1105/tpc.108.065029

Garcia, A. V., Charrier, A., Schikora, A., Bigeard, J., Pateyron, S., de TauziaMoreau, M. L., et al. (2014). Salmonella enterica flagellin is recognized via FLS2 and activates PAMP-triggered immunity in Arabidopsis thaliana. Mol. Plant 7, 657-674. doi: 10.1093/mp/sst145

Garcia, A. V., and Hirt, H. (2014). Salmonella enterica induces and subverts the plant immune system. Front. Microbiol. 5:141. doi: 10.3389/fmicb.2014. 00141

Gemski, P. Jr., and Stocker, B. A. (1967). Transduction by bacteriophage P22 in nonsmooth mutants of Salmonella typhimurium. J. Bacteriol. 93, 1588-1597.

Gorski, L., Parker, C. T., Liang, A., Cooley, M. B., Jay-Russell, M. T., Gordus, A. G., et al. (2011). Prevalence, distribution, and diversity of Salmonella enterica in a 
major produce region of California. Appl. Environ. Microbiol. 77, 2734-2748. doi: 10.1128/AEM.02321-10

Greene, S. K., Daly, E. R., Talbot, E. A., Demma, L. J., Holzbauer, S., Patel, N. J., et al. (2008). Recurrent multistate outbreak of Salmonella newport associated with tomatoes from contaminated fields, 2005. Epidemiol. Infect. 136, 157-165. doi: 10.1017/S095026880700859X

Gupta, S. K., Nalluswami, K., Snider, C., Perch, M., Balasegaram, M., Burmeister, D., et al. (2007). Outbreak of Salmonella braenderup infections associated with Roma tomatoes, northeastern United States, 2004: a useful method for subtyping exposures in field investigations. Epidemiol. Infect. 135, 1165-1173. doi: 10.1017/S0950268807007911

Haefele, D. M., and Lindow, S. E. (1987). Flagellar motility confers epiphytic fitness advantages upon Pseudomonas syringae. Appl. Environ. Microbiol. 53, 2528-2533.

Hagel, G. T., Landis, B. J., and Ahrens, M. C. (1973). Aster leafhopper: source of infestation, host plant preference, and dispersal. J. Econ. Entomol. 66, 877-881.

Haley, B. J., Cole, D. J., and Lipp, E. K. (2009). Distribution, diversity, and seasonality of waterborne salmonellae in a rural watershed. Appl. Environ. Microbiol. 75, 1248-1255. doi: 10.1128/AEM.01648-08

Harshey, R. M. (2003). Bacterial motility on a surface: many ways to a common goal. Annu. Rev. Microbiol. 57, 249-273. doi: 10.1146/annurev.micro.57.030502. 091014

Henrichsen, J. (1972). Bacterial surface translocation: a survey and a classification. Bacteriol. Rev. 36, 478-503.

Henry, E., Yadeta, K. A., and Coaker, G. (2013). Recognition of bacterial plant pathogens: local, systemic and transgenerational immunity. New Phytol. 199, 908-915. doi: 10.1111/nph.12214

Hind, S. R., Strickler, S. R., Boyle, P. C., Dunham, D. M., Bao, Z., O’Doherty, I. M., et al. (2016). Tomato receptor flagellin-sensing 3 binds flgII-28 and activates the plant immune system. Nat. Plants 2:16128. doi: 10.1038/nplants.2016.128

Homma, M., Aizawa, S., Dean, G. E., and Macnab, R. M. (1987a). Identification of the M-ring protein of the flagellar motor of Salmonella typhimurium. Proc. Natl. Acad. Sci. U.S.A. 84, 7483-7487.

Homma, M., Ohnishi, K., Iino, T., and Macnab, R. M. (1987b). Identification of flagellar hook and basal body gene products (FlaFV, FlaFVI, FlaFVII and FlaFVIII) in Salmonella typhimurium. J. Bacteriol. 169, 3617-3624.

Iniguez, A. L., Dong, Y., Carter, H. D., Ahmer, B. M., Stone, J. M., and Triplett, E. W. (2005). Regulation of enteric endophytic bacterial colonization by plant defenses. Mol. Plant Microbe Interact. 18, 169-178. doi: 10.1094/MPMI-180169

Islam, M., Morgan, J., Doyle, M. P., Phatak, S. C., Millner, P., and Jiang, X. (2004a). Fate of Salmonella enterica serovar Typhimurium on carrots and radishes grown in fields treated with contaminated manure composts or irrigation water. Appl. Environ. Microbiol. 70, 2497-2502.

Islam, M., Morgan, J., Doyle, M. P., Phatak, S. C., Millner, P., and Jiang, X. (2004b). Persistence of Salmonella enterica serovar Typhimurium on lettuce and parsley and in soils on which they were grown in fields treated with contaminated manure composts or irrigation water. Foodborne Pathog. Dis. 1, 27-35. doi: 10.1089/153531404772914437

Jahn, C. E., Charkowski, A. O., and Willis, D. K. (2008). Evaluation of isolation methods and RNA integrity for bacterial RNA quantitation. J. Microbiol. Methods 75, 318-324. doi: 10.1016/j.mimet.2008.07.004

Jayaraman, D., Valdes-Lopez, O., Kaspar, C. W., and Ane, J. M. (2014). Response of Medicago truncatula seedlings to colonization by Salmonella enterica and Escherichia coli O157:H7. PLoS One 9:e87970. doi: 10.1371/journal.pone. 0087970

Kallenbach, M., Bonaventure, G., Gilardoni, P. A., Wissgott, A., and Baldwin, I. T. (2012). Empoasca leafhoppers attack wild tobacco plants in a jasmonatedependent manner and identify jasmonate mutants in natural populations. Proc. Natl. Acad. Sci. U.S.A. 109, E1548-E1557. doi: 10.1073/pnas.1200363109

Kearns, D. B. (2010). A field guide to bacterial swarming motility. Nat. Rev. Microbiol. 8, 634-644. doi: 10.1038/nrmicro2405

Kerchev, P. I., Fenton, B., Foyer, C. H., and Hancock, R. D. (2012). Plant responses to insect herbivory: interactions between photosynthesis, reactive oxygen species and hormonal signalling pathways. Plant Cell Environ. 35, 441-453. doi: 10.1111/j.1365-3040.2011.02399.x

Kinkel, L. L. (1997). Microbial population dynamics on leaves. Annu. Rev. Phytopathol. 35, 327-347. doi: 10.1146/annurev.phyto.35.1.327
Klerks, M. M., van Gent-Pelzer, M., Franz, E., Zijlstra, C., and van Bruggen, A. H. (2007). Physiological and molecular responses of Lactuca sativa to colonization by Salmonella enterica serovar Dublin. Appl. Environ. Microbiol. 73, 4905-4914. doi: 10.1128/AEM.02522-06

Koornneef, A., and Pieterse, C. M. (2008). Cross talk in defense signaling. Plant Physiol. 146, 839-844. doi: 10.1104/pp.107.112029

Kunkel, B. N., and Brooks, D. M. (2002). Cross talk between signaling pathways in pathogen defense. Curr. Opin. Plant Biol. 5, 325-331.

Kwan, G., Charkowski, A. O., and Barak, J. D. (2013). Salmonella enterica suppresses Pectobacterium carotovorum subsp. carotovorum population and soft rot progression by acidifying the microaerophilic environment. mBio 4, e557-e512. doi: 10.1128/mBio.00557-12

Kwan, G., Pisithkul, T., Amador-Noguez, D., and Barak, J. (2015). De novo amino acid biosynthesis contributes to Salmonella enterica growth in alfalfa seedling exudates. Appl. Environ. Microbiol. 81, 861-873. doi: 10.1128/AEM.02985-14

Leveau, J. H., and Lindow, S. E. (2001). Appetite of an epiphyte: quantitative monitoring of bacterial sugar consumption in the phyllosphere. Proc. Natl. Acad. Sci. U.S.A. 98, 3446-3453.

Lindow, S. E., Andersen, G., and Beattie, G. A. (1993). Characteristics of insertional mutants of Pseudomonas syringae with reduced epiphytic fitness. Appl. Environ. Microbiol. 59, 1593-1601.

Macnab, R. M. (1996). "Flagella and motility," in Escherichia coli and Salmonella: Cellular and Molecular Biology, eds F. C. Neidhardt and R. Curtiss (Washington, DC: American Society for Microbiology), 123-145.

Mattick, J. S. (2002). Type IV pili and twitching motility. Annu. Rev. Microbiol. 56, 289-314.

Melotto, M., Panchal, S., and Roy, D. (2014). Plant innate immunity against human bacterial pathogens. Front. Microbiol. 5:411. doi: 10.3389/fmicb.2014.00411

Meng, F., Altier, C., and Martin, G. B. (2013). Salmonella colonization activates the plant immune system and benefits from association with plant pathogenic bacteria. Environ. Microbiol. 15, 2418-2430. doi: 10.1111/1462-2920.12113

Mignot, T., Shaevitz, J. W., Hartzell, P. L., and Zusman, D. R. (2007). Evidence that focal adhesion complexes power bacterial gliding motility. Science 315, 853-856. doi: 10.1126/science. 1137223

Miles, P. W. (1972). The saliva of Hemiptera. Adv. Insect Physiol. 9, 183-255.

Monier, J. M., and Lindow, S. E. (2003). Differential survival of solitary and aggregated bacterial cells promotes aggregate formation on leaf surfaces. Proc. Natl. Acad. Sci. U.S.A. 100, 15977-15982.

Mur, L. A., Kenton, P., Atzorn, R., Miersch, O., and Wasternack, C. (2006). The outcomes of concentration-specific interactions between salicylate and jasmonate signaling include synergy, antagonism, and oxidative stress leading to cell death. Plant Physiol. 140, 249-262. doi: 10.1104/pp.105.072348

O'Brien, R. D., and Lindow, S. E. (1989). Effect of plant species and environmental conditions on epiphytic population sizes of Pseudomonas syringae and other bacteria. Phytopathology 79, 619-627.

Painter, J. A., Hoekstra, R. M., Ayers, T., Tauxe, R. V., Braden, C. R., Angulo, F. J., et al. (2013). Attribution of foodborne illnesses, hospitalizations, and deaths to food commodities by using outbreak data. United States, 1998-2008. Emerg. Infect. Dis. 19, 407-415. doi: 10.3201/eid1903.111866

Pena-Cortes, H., Albrecht, T., Prat, S., Weiler, E. W., and Willmitzer, L. (1993). Aspirin prevents wound-induced gene expression in tomato leaves by blocking jasmonic acid biosynthesis. Planta 191, 123-128.

Pieterse, C. M., Van der Does, D., Zamioudis, C., Leon-Reyes, A., and Van Wees, S. C. (2012). Hormonal modulation of plant immunity. Annu. Rev. Cell Dev. Biol. 28, 489-521. doi: 10.1146/annurev-cellbio-092910-154055

Potnis, N., Colee, J., Jones, J. B., and Barak, J. D. (2015). Plant pathogen-induced water-soaking promotes Salmonella enterica growth on tomato leaves. Appl. Environ. Microbiol. 81, 8126-8134. doi: 10.1128/AEM.01926-15

Potnis, N., Soto-Arias, J. P., Cowles, K. N., van Bruggen, A. H., Jones, J. B., and Barak, J. D. (2014). Xanthomonas perforans colonization influences Salmonella enterica in the tomato phyllosphere. Appl. Environ. Microbiol. 80, 3173-3180. doi: 10.1128/AEM.00345-14

Poza-Carrion, C., Suslow, T., and Lindow, S. (2013). Resident bacteria on leaves enhance survival of immigrant cells of Salmonella enterica. Phytopathology 103, 341-351. doi: 10.1094/PHYTO-09-12-0221-FI

Remus-Emsermann, M. N., Tecon, R., Kowalchuk, G. A., and Leveau, J. H. (2012). Variation in local carrying capacity and the individual fate of bacterial colonizers in the phyllosphere. ISME J. 6, 756-765. doi: 10.1038/ismej.2011.209 
Rossez, Y., Wolfson, E. B., Holmes, A., Gally, D. L., and Holden, N. J. (2015). Bacterial flagella: twist and stick, or dodge across the kingdoms. PLoS Pathog. 11:e1004483. doi: 10.1371/journal.ppat.1004483

Rotenberg, D., Thompson, T. S., German, T. L., and Willis, D. K. (2006). Methods for effective real-time RT-PCR analysis of virus-induced gene silencing. J. Virol. Methods 138, 49-59.

Santiviago, C. A., Reynolds, M. M., Porwollik, S., Choi, S. H., Long, F., AndrewsPolymenis, H. L., et al. (2009). Analysis of pools of targeted Salmonella deletion mutants identifies novel genes affecting fitness during competitive infection in mice. PLoS Pathog. 5:e1000477. doi: 10.1371/journal.ppat.1000477

Schikora, A., Carreri, A., Charpentier, E., and Hirt, H. (2008). The dark side of the salad: Salmonella typhimurium overcomes the innate immune response of Arabidopsis thaliana and shows an endopathogenic lifestyle. PLoS One 3:e2279. doi: 10.1371/journal.pone.0002279

Schwachtje, J., and Baldwin, I. T. (2008). Why does herbivore attack reconfigure primary metabolism? Plant Physiol. 146, 845-851. doi: 10.1104/pp.107. 112490

Soto-Arias, J. P., Groves, R., and Barak, J. D. (2013). Interaction of phytophagous insects with Salmonella enterica on plants and enhanced persistence of the pathogen with Macrosteles quadrilineatus infestation or Frankliniella occidentalis feeding. PLoS One 8:e79404. doi: 10.1371/journal.pone.0079404

Soto-Arias, J. P., Groves, R. L., and Barak, J. D. (2014). Transmission and retention of Salmonella enterica by phytophagous hemipteran insects. Appl. Environ. Microbiol. 80, 5447-5456. doi: 10.1128/AEM.01444-14

Spoel, S. H. (2003). NPR1 modulates cross-talk between salicylate- and jasmonatedependent defense pathways through a novel function in the cytosol. Plant Cell 15, 760-770. doi: 10.1105/tpc.009159

Sugio, A., Kingdom, H. N., MacLean, A. M., Grieve, V. M., and Hogenhout, S. A. (2011). Phytoplasma protein effector SAP11 enhances insect vector reproduction by manipulating plant development and defense hormone biosynthesis. Proc. Natl. Acad. Sci. U.S.A. 108, E1254-E1263. doi: 10.1073/pnas. 1105664108

Tornero, P., Conejero, V., and Vera, P. (1994). A gene encoding a novel isoform of the PR-1 protein family from tomato is induced upon viroid infection. Mol. Gen. Genet. 243, 47-53.
Van der Does, D., Leon-Reyes, A., Koornneef, A., Van Verk, M. C., Rodenburg, N., Pauwels, L., et al. (2013). Salicylic acid suppresses jasmonic acid signaling downstream of SCFCOI1-JAZ by targeting GCC promoter motifs via transcription factor ORA59. Plant Cell 25, 744-761. doi: 10.1105/tpc.112. 108548

van Wees, S. C., de Swart, E. A., van Pelt, J. A., van Loon, L. C., and Pieterse, C. M. (2000). Enhancement of induced disease resistance by simultaneous activation of salicylate- and jasmonate-dependent defense pathways in Arabidopsis thaliana. Proc. Natl. Acad. Sci. U.S.A. 97, 8711-8716. doi: 10.1073/pnas. 130425197

Wasala, L., Talley, J. L., Desilva, U., Fletcher, J., and Wayadande, A. (2013). Transfer of Escherichia coli O157:H7 to spinach by house flies, Musca domestica (Diptera: Muscidae). Phytopathology 103, 373-380. doi: 10.1094/PHYTO-09-12-0217-FI

Wei, J., van Loon, J. J., Gols, R., Menzel, T. R., Li, N., Kang, L., et al. (2014). Reciprocal crosstalk between jasmonate and salicylate defence-signalling pathways modulates plant volatile emission and herbivore host-selection behaviour. J. Exp. Bot. 65, 3289-3298. doi: 10.1093/jxb/eru181

Wilkinson, T., Ashford, D., Pritchard, J., and Douglas, A. (1997). Honeydew sugars and osmoregulation in the pea aphid Acyrthosiphon pisum. J. Exp. Biol. 200(Pt 15), 2137-2143.

Yi, S. Y., Shirasu, K., Moon, J. S., Lee, S. G., and Kwon, S. Y. (2014). The activated SA and JA signaling pathways have an influence on flg22-triggered oxidative burst and callose deposition. PLoS One 9:e88951. doi: 10.1371/journal.pone.0088951

Conflict of Interest Statement: The authors declare that the research was conducted in the absence of any commercial or financial relationships that could be construed as a potential conflict of interest.

Copyright (c) 2018 Cowles, Groves and Barak. This is an open-access article distributed under the terms of the Creative Commons Attribution License (CC BY). The use, distribution or reproduction in other forums is permitted, provided the original author(s) and the copyright owner(s) are credited and that the original publication in this journal is cited, in accordance with accepted academic practice. No use, distribution or reproduction is permitted which does not comply with these terms. 